\title{
Traditional Human Taste Panel and Taste Sensors Methods for Bitter Taste Masking Research on Combined Bitterness Suppressants of Berberine Hydrochloride
}

\author{
Rui-xin Liu, ${ }^{1,2,3 \#}$ Xiao-jie Gao, ${ }^{4 \#}$ Jun-ming Wang, ${ }^{4}$ Li-ping Dai, ${ }^{4}$ Bing-ya Kang, ${ }^{1,2,3}$ \\ Lu Zhang, ${ }^{1,2,3}$ Jun-han Shi, ${ }^{1,2,3}$ Xin-jing Gui, ${ }^{4}$ Pei Liu, ${ }^{1}$ and Xue-lin $\mathrm{Li}^{1 *}$ \\ ${ }^{1}$ Department of Pharmacy, The First Affiliated Hospital of Henan University of Traditional Chinese Medicine, \\ Zhengzhou 450000, Henan, China \\ ${ }^{2}$ The Level Three Laboratory of Chinese Traditional Medical Preparation of State Administration of TCM, \\ Zhengzhou 450000, Henan, China \\ ${ }^{3}$ Key Laboratory of Viral Diseases Prevention and Treatment of TCM of Henan Province, \\ Zhengzhou 450000, Henan, China \\ ${ }^{4}$ School of Pharmacy, Henan University of Traditional Chinese Medicine, Zhengzhou 450008, Henan, China
}

(Received July 8, 2016; accepted August 19, 2016)

Keywords: traditional human taste panel method, taste sensors, bitterness suppressant, taste masking

Bitterness suppressants (BSs) can improve the taste of bitter medicines and mask the taste of bitter foodstuffs. Our goal here was to establish a method of analyzing bitterness using both a traditional human taste panel method (THTPM) and a taste sensors method. Sucralose (SL), sodium ferulate $(\mathrm{SF})$, and $\beta$-cyclodextrin $(\beta-\mathrm{CD})$, and their combinations were tested for their abilities to mask the bitter taste of berberine hydrochloride (BBR). SF showed a weak effect in masking the bitter taste of BBR, whereas SL and $\beta-C D$ showed stronger effects. The effect of SL on bitter taste masking was linear with the logarithm of concentration, while the effect of $\beta-C D$ was linear with its concentration. When $\beta-C D$ and SL were used in combination, $\beta-C D$ played a major role in taste masking. For this combination, a good correlation was found between the indices of THTPM and the taste sensors method. The taste sensors method can accurately predict the intensity of bitterness of BBR. Thus, it can be an effective tool for the screening of BS of BBR and the study of the taste-masking characteristics of BS combinations.

\section{Introduction}

The bitterness of orally administered drugs is an important factor affecting patient compliance. ${ }^{(1)}$ Some of the most commonly used bitter-tasting drugs include aspirin, naproxen, and quinine. Recently, research into drug taste masking has been highlighted in the popular press $^{(2-5)}$ with taste masking using bitterness suppressants (BSs) as an important topic. ${ }^{(6-10)}$ BSs compensate for the bitter substance by blocking bitter taste receptors, truncating the bitterness signal transmission or by offering an even greater signal to the sweet receptors. BSs have different mechanisms. For instance, the sweetener sucralose (SL) fires impulses in the central nervous system and compensates for the bitter taste. ${ }^{(11)} \beta$-cyclodextrin $(\beta-\mathrm{CD})$ includes bitter substances to reduce the apparent bitter

"Corresponding author: e-mail: xuelinli450000@163.com

\#Contributed equally

http://dx.doi.org/10.18494/SAM.2017.1432

ISSN 0914-4935 C MYU K.K. 
concentration for bitterness suppression. ${ }^{(12)}$ As a sodium salt with natural bitterness suppression, ferulic acid and sodium ferulate (SF) play important roles in the suppression of bitterness. ${ }^{(13)}$

A single BS generally cannot achieve good bitterness suppression effects on highly bitter single-ingredient medications or compound drugs. The BS molecule(s) and the species producing bitterness must be compatible for the effect to be pronounced. Therefore, it is important that pharmacists studying taste masking appreciate the laws of mutual compatibilities of different BSs. However, it is often quite difficult to know a priori what the proper compatibilities will be. That is, it is not always possible to know that BS "type X" will be a good fit for active pharmaceutical ingredient "type Y". Furthermore, there is no data on the effects of different combinations of BS components. Thus, a large amount of empirical testing is needed to correctly match the BS or groups of BS to the drug in question.

Such empirical testing generally uses traditional human taste panel method (THTPM), but this is not ideal ${ }^{(14-16)}$ because it is costly, time-consuming, and prone to bias and human error. ${ }^{(17)}$ It is also quite dangerous and unethical for humans to consume an unprescribed active pharmaceutical ingredient. Furthermore, THTPM often requires repeat and parallel testing - this is particularly dangerous because this would imply that test subjects repeatedly take a certain medication. It is also possible to have dangerous overdose effects because obtaining a proper match between a drug and a BS on the first trial is rare. While spacing out the dosing or using new human test subjects can eliminate overdose effects, this still increases costs and introduces even additional errors. Indeed, power calculations for human taste testing imply a large $\mathrm{n}$ owing to the relatively high standard deviation between replicates. ${ }^{(18)}$

To solve these major limitations, taste sensors have recently been adopted for taste testing. The taste sensors are a taste analysis technology that features low costs, fast and safe operation, and relatively objective outcome metrics - these features compensate for the THTPM's weaknesses and have encouraged large-scale replacement of human-based testing, especially for medicinal products. ${ }^{(19)}$ Taste sensors offer coherent and multiplexed tasting and are an intelligent electronic identification system that reflects the overall taste profile of samples. The surface is covered with sensors whose material is similar to biological systems and serves as sensory membranes. Gustatory substances stimulate this membrane after absorption. The taste sensors have been applied in the food industry for more than 20 years especially in food traceability, ${ }^{(20)}$ food freshness, ${ }^{(21)}$ food quality, ${ }^{(22-24)}$ and safety tests. ${ }^{(25,26)}$ It has increasingly been applied to pharmaceutical fields including the evaluation of drug bitterness and taste masking studies. ${ }^{(3,27-29)}$

Despite the reports of bitterness research using taste sensors, the literature has been largely silent on the utility of this novel scheme for traditional Chinese medicines. The importance of this class of drug is growing rapidly, but the bitterness masking is particularly challenging because of a wide variety of inactive ingredients present in these herbal decoctions and infusions. Here, we used berberine hydrochloride (BBR) as a representative drug with a bitter taste. BBR is the active substance in the traditional Chinese medicine Rhizoma coptidis. BBR is a good model drug for taste masking research because of its pure bitter taste, low cost, and safety. We then chose three BSs with different taste-masking mechanisms. We used a uniform design method, and the bittertaste-masking characteristics of different combinations of two of the three BSs were studied by both a THTPM method and the taste sensors method. The effects of these different combinations of BSs were evaluated and the correlation between the two methods was compared to validate this novel approach for this class of drug. To the best of our knowledge, this is the first report to describe 
bitterness masking in a quantitative manner with taste sensors in traditional Chinese medicines. The results pave the way for advanced formulations of this class of drug without laborious and expensive human testing.

\section{Materials and Methods}

\subsection{Materials}

We purchased BBR (solid, purity 98.62\%, Sichuan Province Yuxin Pharmaceutical Co., batch 140406), $\beta$-CD (solid, purity $\geq 98 \%$, Qufu Tianli Medical Supplements Co., batch 141002), SF (solid, purity $\geq 98 \%$, Shanghai Boylechem Co. batch AN0120622), and SL (solid, purity $\geq 98.89 \%$, Beijing Zoman Biotechnology Co., batch 1324030).

TS-5000Z taste sensors (Intelligent Sensor Technology, Inc.) were used for testing including the sensors AE1, C00, AN0, and BT0. There were used to measure astringent, acidic bitter materials, basic bitter materials, and bitter hydrochloride salts, respectively. Other equipment included an electronic balance (Sartorius, BSA224S-CW), a KUDOS desktop ultrasonic cleaner (HK250), and a magnetic stirrer (AM-5250B). The uniform design experiment result was based on the modeling and operation of SAS and Matlab.

\subsection{Uniform design}

Combinations of two of the three BSs at different concentrations were designed. Experiments were arranged with a uniform design for three factors and five levels $\left[\mathrm{U}_{5}\left(5^{3}\right)\right]$ (Tables 1-4).

Table 1

Uniform design table for the optimization of the SF and SL combination.

\begin{tabular}{lcc}
\hline No. & $\begin{array}{c}\text { Concentration of SF } \\
(\mathrm{mg} / \mathrm{mL})\end{array}$ & $\begin{array}{c}\text { Concentration of SL } \\
(\mathrm{mg} / \mathrm{mL})\end{array}$ \\
\hline 1 & 1.00 & 0.20 \\
2 & 2.00 & 0.40 \\
3 & 3.00 & 0.10 \\
4 & 4.00 & 0.30 \\
5 & 5.00 & 0.50 \\
\hline
\end{tabular}

Table 3

Uniform design table for the optimization of the SL and $\beta$-CD combination (THTPM).

\begin{tabular}{lcc}
\hline No. & $\begin{array}{c}\text { Concentration of SL } \\
(\mathrm{mg} / \mathrm{mL})\end{array}$ & $\begin{array}{c}\text { Concentration of } \beta-\mathrm{CD} \\
(\mathrm{mg} / \mathrm{mL})\end{array}$ \\
\hline 1 & 0.10 & 20.00 \\
2 & 0.20 & 40.00 \\
3 & 0.30 & 10.00 \\
4 & 0.40 & 30.00 \\
5 & 0.50 & 50.00 \\
\hline
\end{tabular}

Table 2

Uniform design table for the optimization of the SF and $\beta-C D$ combination.

\begin{tabular}{lcc}
\hline No. & $\begin{array}{c}\text { Concentration of SF } \\
(\mathrm{mg} / \mathrm{mL})\end{array}$ & $\begin{array}{c}\text { Concentration of } \beta-\mathrm{CD} \\
(\mathrm{mg} / \mathrm{mL})\end{array}$ \\
\hline 1 & 1.00 & 20.00 \\
2 & 2.00 & 40.00 \\
3 & 3.00 & 10.00 \\
4 & 4.00 & 30.00 \\
5 & 5.00 & 50.00 \\
\hline
\end{tabular}

Table 4

Design table for the optimization of the SL and $\beta-C D$ combination (taste sensors).

\begin{tabular}{lcc}
\hline No. & $\begin{array}{c}\text { Concentration of SL } \\
(\mathrm{mg} / \mathrm{mL})\end{array}$ & $\begin{array}{c}\text { Concentration of } \beta-\mathrm{CD} \\
(\mathrm{mg} / \mathrm{mL})\end{array}$ \\
\hline 1 & 0.006 & 1.20 \\
2 & 0.012 & 2.40 \\
3 & 0.018 & 0.60 \\
4 & 0.024 & 1.80 \\
5 & 0.030 & 3.00 \\
\hline
\end{tabular}




\subsection{THTPM method}

\subsubsection{Sample preparation}

Positive and negative reference solution preparations: $15.20 \mathrm{~g}$ of BBR was weighed, dissolved in $2 \mathrm{~L}$ of water, and mixed as a positive reference solution $(I=2.5)$. Then, $1 \mathrm{~L}$ of water was placed in a $1 \mathrm{~L}$ beaker as a negative reference solution without bitterness.

For the test solution, we prepared $0.2 \mathrm{~g}$ of BBR in $4000 \mathrm{~mL}$ of purified water. This 0.05 $\mathrm{mg} \cdot \mathrm{mL}^{-1}$ stock solution was used as prepared. Five portions $(600 \mathrm{~mL}$ per portion) were added to create the following mixtures: (1) $0.60 \mathrm{~g}$ of SF $\left(1 \mathrm{mg} \cdot \mathrm{mL}^{-1}\right)$ and $0.12 \mathrm{~g}$ of SL $\left(0.2 \mathrm{mg} \cdot \mathrm{mL}^{-1}\right),(2)$ $0.12 \mathrm{~g}$ of SF $\left(2 \mathrm{mg} \cdot \mathrm{mL}^{-1}\right)$ and $0.24 \mathrm{~g}$ of SL $\left(0.4 \mathrm{mg} \cdot \mathrm{mL}^{-1}\right)$, (3) $1.81 \mathrm{~g}$ of SF $\left(3 \mathrm{mg} \cdot \mathrm{mL}^{-1}\right)$ and 0.06 $\mathrm{g}$ of SL $\left(0.1 \mathrm{mg} \cdot \mathrm{mL}^{-1}\right)$, (4) $2.42 \mathrm{~g}$ of SF $\left(4 \mathrm{mg} \cdot \mathrm{mL}^{-1}\right)$ and $0.18 \mathrm{~g}$ of SL $\left(0.3 \mathrm{mg} \cdot \mathrm{mL}^{-1}\right)$, and (5) $3.02 \mathrm{~g}$ of $\mathrm{SF}\left(5 \mathrm{mg} \cdot \mathrm{mL}^{-1}\right)$ and $0.32 \mathrm{~g}$ of SL $\left(0.5 \mathrm{mg} \cdot \mathrm{mL}^{-1}\right)$. The samples $\mathrm{S}_{2}, \mathrm{~S}_{3}, \ldots, \mathrm{S}_{6}$, and stock solution $\mathrm{S}_{1}$ were prepared for a total of 6 samples. These were tasted and evaluated as the first set of samples. Similarly, the second and third sets of samples were obtained (the dosage of $\beta-C D$ is $\left.10-50 \mathrm{mg} \cdot \mathrm{mL}^{-1}\right)$.

\subsubsection{Determination procedure}

We used a method based on the literature. ${ }^{(30)}$ Firstly, strict screeing including bitter taste sensitivity was conducted to recruit volunteers. This study was conducted in accordance with the Declaration of Helsinki and with approval from the Ethics Committee of the First Affiliated Hospital of Henan University of Traditional Chinese Medicine (Zhengzhou, China). Written informed consent was obtained from all participants. Secondly, the $30 \mathrm{~mL}$ negative and positive reference solutions were placed in a paper cup. Volunteers held this in their mouth for $15 \mathrm{~s}$. They then gargled to ensure that the bitterness was distributed throughout the sensitive area in the lingual radix and lingual side. After being told the classification and specific value of the intensity of bitterness in this solution, the volunteers spat it out and gargled 5 times until no bitter taste remained in the mouth. After 1-2 min, the test sample solution was measured and compared with the reference solution. The volunteers gave it a specific intensity of bitterness. This was recorded on a predesigned "drug bitterness sort and score table". There was $1 \mathrm{~h}$ of rest time between each round. The subjects used a randomized and single-blind method for sample testing. Lastly, the volunteers may have individual differences and several outliers emerged among the experimental data. The outliers were tested and removed using the Grubbs' testing method, only one outlier was removed in each cycle. Oversized and undersized outliers may exist in taste experiments, so the statistical tests used in this study were two-sided. The significance and rejection levels were set as 0.1 and 0.05 , respectively.

\subsubsection{Index selection}

The reduction of intensity of bitterness $(\Delta I)$ is taken as an index. $I$ is a measurement of intensity of bitterness. The formula is as follows:

$$
I=\frac{I_{1}+I_{2}+\cdots+I_{n}}{n}(n \geq 20),
$$


where $n$ is the number of effective volunteers, and $I_{1}, I_{2}, \ldots, I_{n}$ are the specific results of each. In THTPM, the taste-masking effect can be evaluated on the basis of $\Delta I$. The formula is as follows:

$$
\Delta I=I_{b}-I_{a},
$$

where $I_{b}$ is the intensity of bitterness before taste masking whereas $I_{a}$ is the intensity of bitterness after taste masking.

\subsection{Taste sensors method}

\subsubsection{Working principle of taste sensors}

TS-5000Z taste sensors, which employ the same mechanism as that of the human tongue, convert the taste of various substances into numerical data. In the entire measurement process, the taste sensor should exhibit global selectivity so that it responds consistently to the same taste similarly to the human tongue. TS-5000Z taste sensors based on the artificial lipid membranes, which are composed of lipids, plasticizers, and polyvinyl chloride, consistently respond to tastes similar to those detected by the human tongue. The response principle is that the lipid in the taste sensors interacts with various taste materials via electrostatic and hydrophobic interactions, which cause a change in the potential of the lipid membrane. The change is detected by a computer to provide a sensor output. ${ }^{(31)}$

\subsubsection{Sample preparation}

We made $0.1 \mathrm{mg} \mathrm{mL}^{-1} \mathrm{BBR}$ and $1 \mathrm{mg} \mathrm{mL}^{-1} \mathrm{SL}$ stock solutions, both in $10 \mathrm{mM} \mathrm{KCl}$. We combined five $3 \mathrm{~mL}$ portions of the BBR stock solution with: (1) $0.6 \mathrm{~mL}$ of SL stock solution and $120 \mathrm{mg}$ of $\beta-\mathrm{CD}$, (2) $1.2 \mathrm{~mL}$ of SL stock solution and $240 \mathrm{mg}$ of $\beta-\mathrm{CD}$, (3) $1.8 \mathrm{~mL}$ of SL stock solution and $60 \mathrm{mg}$ of $\beta-\mathrm{CD}$, (4) $2.4 \mathrm{~mL}$ of SL stock solution and $180 \mathrm{mg}$ of $\beta-\mathrm{CD}$, and (5) $3.0 \mathrm{~mL}$ of SL stock solution and $300 \mathrm{mg}$ of $\beta$-CD. These were dissolved with a $10 \mathrm{mM} \mathrm{KCl}$ solution for a total volume of $100 \mathrm{~mL}$. Samples $\mathrm{S}_{2}{ }^{\prime}, \mathrm{S}_{3}{ }^{\prime}, \ldots, \mathrm{S}_{6}{ }^{\prime}$ and the BBR stock solution $\mathrm{S}_{1}{ }^{\prime}$ for a total of 6 samples were obtained for the evaluation of taste sensors.

\subsubsection{Determination procedure}

After cleaning the sensors for $90 \mathrm{~s}$ in a purification bath, the sensors were placed in a reference solution for cleaning for $120 \mathrm{~s}$. This was followed by the second reference solution for $120 \mathrm{~s}$. The sensors were set to zero after $30 \mathrm{~s}$ of equilibration. After reaching equilibrium conditions, the testing began for $30 \mathrm{~s}$. After a brief cleaning in the two reference solutions for $3 \mathrm{~s}$ each, the sensors were placed in a new reference solution to detect aftertaste for $30 \mathrm{~s}$. This cycle was repeated four times. After removing the results of the first cycle, the average data of the later three cycles was defined as the test result. The solutions of each cleaning, balancing, and aftertaste testing were distributed in different sample cups. ${ }^{(32)}$

The TS-5000Z taste analysis system includes eight taste sensors. These include the umami sensor AAE, the saltiness sensor $\mathrm{CT} 0$, the sour sensor CA0, the acidic bitterness sensor $\mathrm{C} 00$, the basic bitterness sensor AN0, the hydrochloride salts bitterness sensor BT0, the astringent sensor 
AE1, and the sweet taste sensor GL1. We selected the bitterness sensors C00, AN0, and BT0, and the astringency sensor AE1 because the present evaluation used BBR from Rhizoma coptidis that has both taste types.

\subsubsection{Index selection}

The taste sensors test program is shown in Fig. 1. Figure 1 highlights how the voltage changes that result from the various stimuli are interpreted as a measurement of taste. The relative value $(R)$ and the change in membrane potential caused by adsorption $(C P A)$ in the TS-5000Z taste analysis system are expressed as

$$
\begin{gathered}
R=V s-V r, \\
C P A=V r^{\prime}-V r .
\end{gathered}
$$

The $C P A$ values of the bitter taste sensors $\mathrm{C} 00, \mathrm{AN} 0$, and $\mathrm{BT} 0$, and the astringent sensor $\mathrm{AE} 1$ can reflect the samples' taste information. ${ }^{(33)}$ Thus, the reduction of $C P A(\triangle C P A)$ was used to evaluate the taste-masking effect. The formula can be expressed as

$$
\triangle C P A=C P A_{b}-C P A_{a} .
$$

Here, the subscripts $b$ and $a$ indicate before and after masking, respectively.

\section{Results}

\subsection{THTPM method}

\subsubsection{Optimization of the SF and SL combination}

The regression model for the SF and SL combination is shown in Fig. 2 with the following regression equation: $\Delta I=0.01819 \log C_{S F}+0.3312 \log C_{S L}+2.278\left(R^{2}=0.9635, p<0.05, R M S E=\right.$ 0.05902). Here, $C_{S F}$ is the concentration of SF while $C_{S L}$ is the concentration of SL. $C_{S F} p>0.05$ and $C_{S L} p<0.05$, which illustrate that SL is the major factor and is proportional to $\Delta I$.

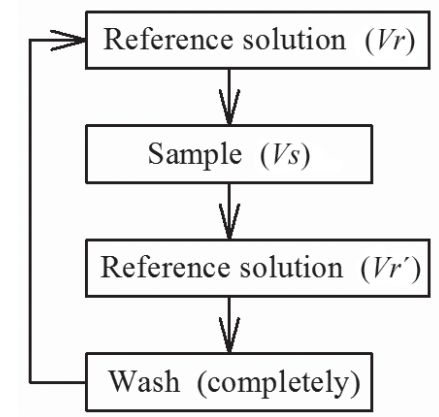

Fig. 1. Taste sensors test program and anaysis approach. 


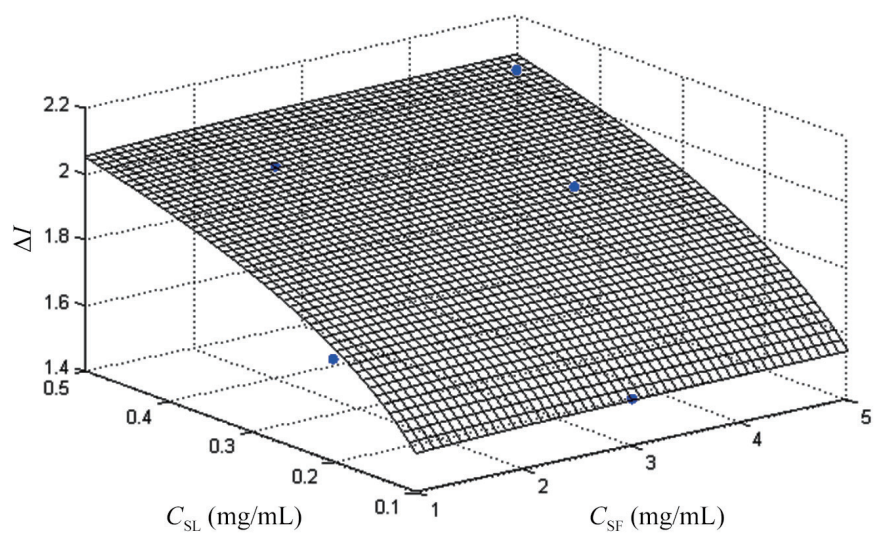

Fig. 2. (Color online) Regression model of taste-masking effect of combination of SF and SL.

\subsubsection{Optimization of the SF and $\beta-C D$ combination}

The regression model for the $\mathrm{SF}$ and $\beta$-CD combination is shown in Fig. 3 with the following regression equation: $\Delta I=0.00733 C_{S F}+0.01513 C_{C D}+1.0150\left(R^{2}=0.9500, p<0.05, R M S E=0.07958\right)$. Here, $C_{S F}$ is the concentration of SF while $C_{C D}$ is the concentration of $\beta-\mathrm{CD} . C_{S F} p>0.05$ and $C_{C D} p$ $<0.05$, which illustrate that $\beta-\mathrm{CD}$ is the major factor and is proportional to $\Delta I$.

\subsubsection{Optimization of SL and $\beta-C D$ combination}

The regression model for the SL and $\beta$-CD combination based on THTPM is shown in Fig. 4 with the following regression equation: $\Delta I=0.5900 C_{S L}+0.0143 C_{C D}+1.3050\left(R^{2}=0.9806, p<0.05\right.$, $R M S E=0.05657)$ where $C_{S L}$ is the concentration of SL while $C_{C D}$ is the concentration of $\beta-C D . C_{S L}$ $p>0.05$ and $C_{C D} p<0.05$, which illustrate that $\beta-C D$ is the major factor and is proportional to $\Delta I$.

\subsection{Taste sensors method}

\subsubsection{Sensor selection for BBR bitterness analysis}

We used the sensors $\mathrm{C} 00, \mathrm{AE} 1, \mathrm{AN} 0$, and BT0. These four sensors were applied to the BBR solutions of $0.1,0.3,1,3,10,30,50$, and $100 \mathrm{mg} \cdot \mathrm{mL}^{-1}$. The results showed that there was no response from sensor $\mathrm{C} 00$ or sensor AE1 at any concentration. Sensor AN0 had a slight response to concentrations over $10 \mathrm{mg} \cdot \mathrm{mL}^{-1}$. Only sensor BT0 had an overall response to BBR solutions of $0.1-100$ $\mathrm{mg} \cdot \mathrm{mL}^{-1}$.

The above-mentioned four sensors were also applied to BBR-free negative samples (Table 4). The results showed that the four sensors had no obvious response to the SL and $\beta$-CD combination at different proportions. Thus, the effect of BSs on sensor output can be excluded. Thus, selecting the response value of the hydrochloride salts bitterness sensor BT0 the for bitterness analysis of BBR is consistent with the fact that BBR is a base salt (Fig. 5). 


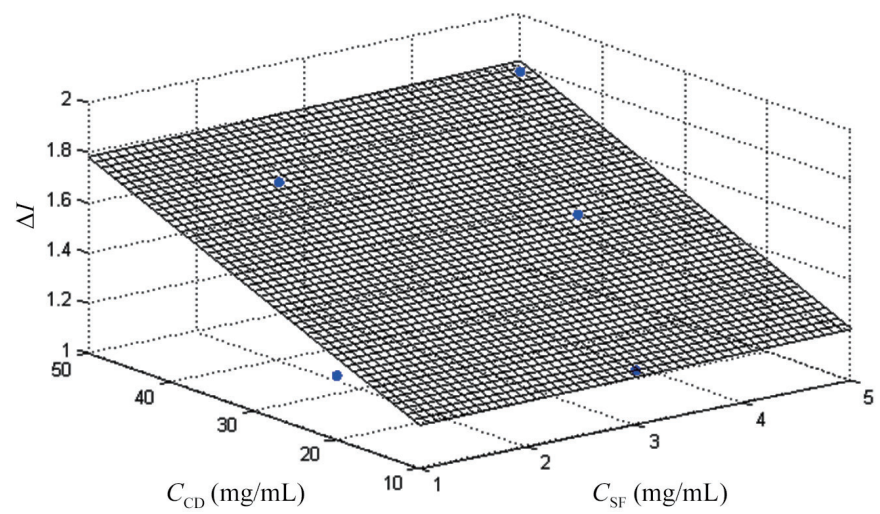

Fig. 3. (Color online) Regression model of taste-masking effect of combination of SF and $\beta$-CD.

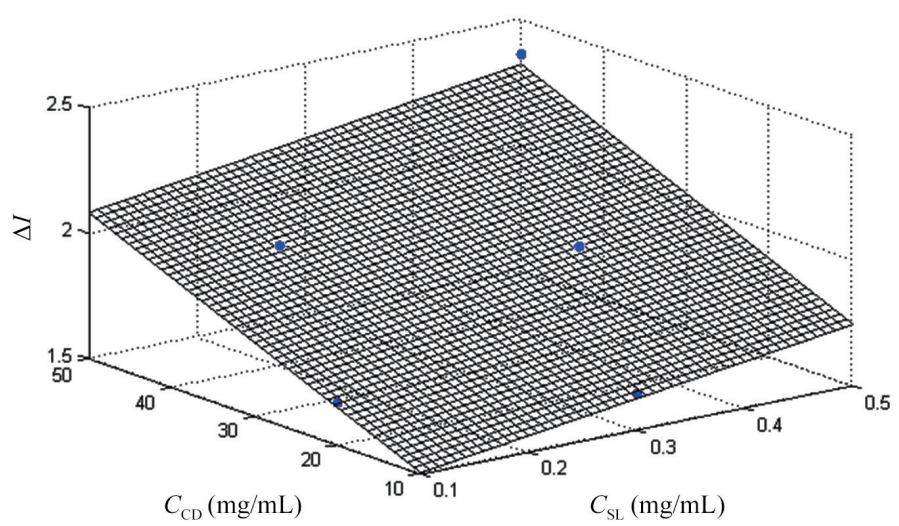

Fig. 4. (Color online) Regression model of taste-masking effect of combination of SL and $\beta$-CD (THTPM).

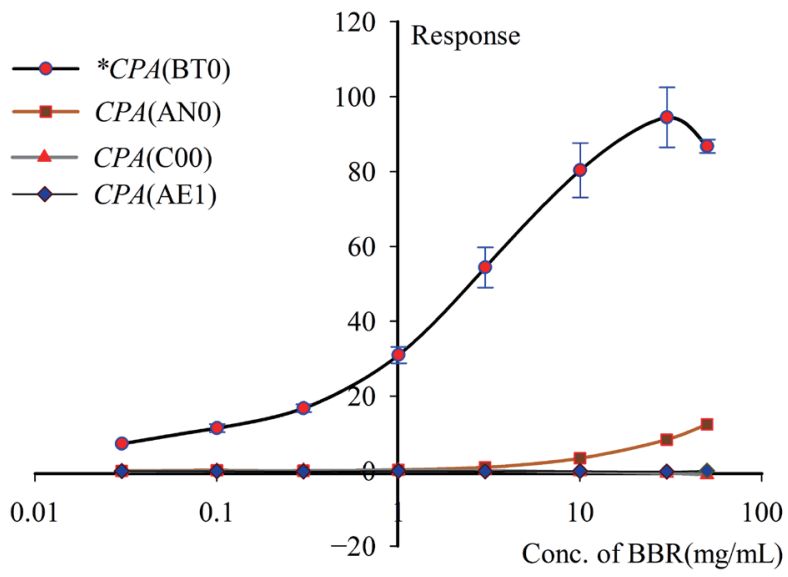

Fig. 5. (Color online) Response curve of taste sensors in different concentrations of BBR.

\subsubsection{Concentration selection for samples in taste sensors}

As Fig. 5 shows, the sensor BT0 has an overall response to BBR solutions of $0.1-100 \mathrm{mg} \cdot \mathrm{mL}^{-1}$. It has a linear output within $0.1-10 \mathrm{mg} \cdot \mathrm{mL}^{-1}$. Consequently, the concentration of $3 \mathrm{mg} \cdot \mathrm{mL}^{-1}$ was chosen for BS testing. To ensure the consistency between the taste sensors test sample and the 
human taste test sample, the concentrations of SL and $\beta-C D$ were reduced proportionally for the taste sensors test sample - that is, the percentages of BBR, SL, and $\beta$-CD remain the same between the two samples.

\subsubsection{Regression analysis of SL and $\beta-C D$ combination}

The regression model of the SL and $\beta-C D$ combination based on the taste sensors is shown in Fig. 6 with the following regression equation: $\triangle C P A=2.5560 C_{S L}+0.8656 C_{C D}+0.7340\left(R^{2}=0.9932\right.$, $p<0.05, R M S E=0.09442$ ) where $\triangle C P A$ is the result of sensor BT0, $C_{S L}$ is the concentration of SL, and $C_{C D}$ is the concentration of $\beta-C D . C_{S L} p>0.05$ and $C_{C D} p<0.05$, which illustrate that $\beta-C D$ is the major factor and is proportional to $\triangle C P A$. This agrees with the result obtained by the THTPM method.

\subsection{Correlation analysis of taste test results and taste sensors test results}

We performed regression analysis between SL and $\beta$-CD using THTPM and taste sensors data. The relationship between $\triangle I$ and $\triangle C P A$ of sensor BT0 is shown in Fig. 7. The results showed a good linear relationship between $\triangle I$ and $\triangle C P A\left(R^{2}=0.8860, p<0.05\right)$. This suggests that the taste

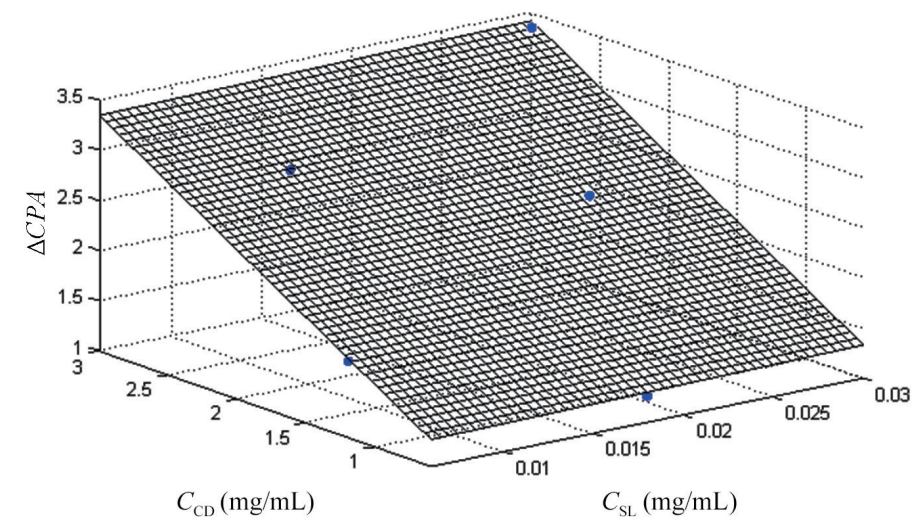

Fig. 6. (Color online) Regression model of taste-masking effect of combination of SL and $\beta$-CD (taste sensors method).

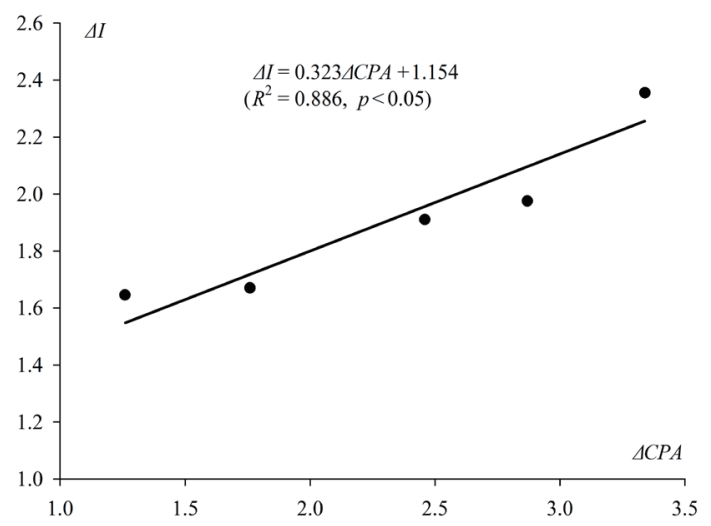

Fig. 7. Correlation of taste-sensors-based and THTPM-based compatibilities of SL and $\beta$-CD on BBR. 
sensors can accurately predict the intensity of bitterness of BBR. It is an effective tool to screen the $\mathrm{BS}$ of BBR and perform taste masking research.

\section{Discussion}

\subsection{Taste-masking effect analysis of three BSs}

The results showed that any two ingredients from SL, SF, and $\beta-C D$ used together can significantly reduce the intensity of bitterness of BBR. Results of the taste-masking ability tests of SF combined with SL or $\beta$-CD showed that SF had a weak taste-masking effect, which is not significant $(p>0.05)$. The results also highlight the significant taste-masking effect of SL $(p<0.05)$. It is proportional to the logarithm of its concentration. $\beta$-CD also has a significant taste-masking effect $(p<0.05$ ), which is proportional to its concentration. In the combination of $\beta-C D$ and SL, $\beta$-CD plays a vital role in taste masking while the role of SL is insignificant.

\subsection{Taste-masking mechanism of SL and $\beta-C D$}

The taste-masking characteristics of the SL and $\beta$-CD combination depend on the taste-masking mechanisms and characteristics of both ingredients. SL is a high-potency sweetener whose taste effect and concentration conform to the Weber-Fechner Law (WFL), that is, the sensation intensity is proportional to the logarithm of concentration. ${ }^{(34-36)}$ The mechanism of the taste-masking effect of $\beta-C D$ is the inclusion principle. ${ }^{(37-40)}$ It can enclose a certain amount of bitter drugs into its cavity. Thus, the taste-masking effect is proportional to the amount of $\beta-\mathrm{CD}$.

\subsection{Regression modeling}

We established a model using multiple linear regression analysis. At first, we did not obtain a good regression equation when SL was included. However, a good regression model was obtained after we performed logarithm transformation on the SL data. This highlights the importance of using pharmaceutical and chemical knowledge to carry out the necessary analysis and transformations.

\subsection{Uniform design majorization}

The uniform design approach is a "Quasi-Monte Carlo" method in number theory. Here, the test points show "uniformity and decentralization". This means a better representation of the test results, and thus the number of experiments needed is markedly reduced. However, the design does not offer "orderliness and comparability". Thus, variance analysis cannot be performed directly. Consequently, it is particularly important to use accurate and appropriate mathematical methods to establish models and optimize them. ${ }^{(41)}$ The commonly used mathematical modeling methods are stepwise multiple regression, artificial neural network modeling, ${ }^{(42)}$ and the B-spline functions modeling. In this paper, we used multivariate regression modeling. 


\section{Conclusions}

For the BBR solution, SF shows a weak effect in bitter taste masking, while SL and $\beta-C D$ show significant effects. The effect of SL on bitter taste-masking is linear with the logarithm of its concentration. The effect of $\beta-C D$ is linear with its concentration. When $\beta-C D$ and SL are used together, $\beta$-CD plays a major role in taste-masking.

The taste sensors method quantitates how SL and $\beta$-CD suppress the bitterness of BBR. The taste sensors correlate linearly with THTPM - this indicates that the taste sensors accurately predict the intensity of bitterness of BBR. It is an effective tool to screen the BS of BBR and study the taste-masking characteristics of BS.

The limitations of this study include the relatively low number of samples, but work is under way in our laboratory to address this. We are also intersted in expanding the types of traditional Chinese medicines under study and will include active pharmaceutical ingredients besides BBR. Nevertheless, this work offers exciting and preliminary results that highlight the power of taste sensors to rapidly analyze this unique niche of modern pharmacopeia.

\section{Acknowledgements}

We thank the National Natural Science Foundation of China (Grant No. 81001646), the Traditional Chinese Medicine Administration of the Traditional Chinese Medicine Scientific special subject of Henan Province (Grant No. 2014ZY02066), the Henan College of Fundamental Research in Provincial Universities nurture gifted youth project (2014KYYWF-YQ01), and the Tianjiang Pharmaceutical Collaborative Projects (XZ2011030042).

\section{References}

1 J. A. Mennella, A. C. Spector, D. R. Reed, and S. E. Coldwell: Clin. Ther. 35 (2013) 1225.

2 A. Tanigake, Y. Miyanaga, T. Nakamura, E. Tsuji, K. Matsuyama, M. Kunitomo, and T. Uchida: Chem. Pharm. Bull. 51 (2003) 1241.

3 T. Harada, T. Uchida, M. Yoshida, Y. Kobayashi, R. Narazaki, and T. Ohwaki: Chem. Pharm. Bull. 58 (2010) 1009.

4 J. N. Coupland and J. E. Hayes: Pharm. Res. 31 (2014) 2921.

5 Y. Wei, M. P. Nedley, S. B. Bhaduri, X. Bredzinski, and S. H. Boddu: AAPS Pharm. Sci. Tech. 16 (2015) 455.

6 Z. Ayenew, V. Puri, L. Kumar, and A. K. Bansal: Recent Pat. Drug. Deliv. Formul. 3 (2009) 26.

7 J. Y. Zheng and M. P. Keeney: Int. J. Pharm. 310 (2006) 118.

8 O. Rachid, F. E. Simons, M. Rawas-Qalaji, and K. J. Simons: AAPS Pharm. Sci. Tech. 11 (2010) 550.

9 J. A. Mennella, D. R. Reed, P. S. Mathew, K. M. Roberts, and C. J. Mansfield: Chem. Sens. 40 (2015) 17.

10 R. Liu, H. Li, X. Li, X. Zhang, and J. Qiu: Chin. Traditional Herbal Drugs 44 (2013) 2240.

11 X. Li, J. Qiu, R. Liu, and J. Shi: Chin. J. Exp. Traditional Med. Formulae 18 (2012) 335.

12 J. Shi, X. Zhang, J. Qiu, X. Li, and R. Liu: Chin. J. Exp. Traditional Med. Formulae 19 (2013) 1.

13 W. Wang and J. Zheng: China Condiment 31 (2006) 13.

14 T. Ishizaka, Y. Miyanaga, J. Mukai, K. Asaka, Y. Nakai, E. Tsuji, and T. Uchida: Chem. Pharm. Bull. 52 (2004) 943.

15 L. Sipos, Z. Kovacs, V. Sagi-Kiss, T. Csiki, Z. Kokai, A. Fekete, and K. Heberger: Food Chem. 135 (2012) 2947.

16 T. H. Hoang Thi, S. Morel, F. Ayouni, and M. P. Flament: Int. J. Pharm. 434 (2012) 235.

17 M. Ito, K. Ikehama, K. Yoshida, T. Haraguchi, M. Yoshida, K. Wada, and T. Uchida: Int. J. Pharm. 441 (2013) 121.

18 S. D. Halpern, J. H. Karlawish, and J. A. Berlin: JAMA 288 (2002) 358. 
19 E. A. Baldwin, J. Bai, A. Plotto, and S. Dea: Sensors 11 (2011) 4744.

20 M. Gutiérrez-Capitán, J. L. Santiago, J. Vila-Planas, A. Llobera, S. Boso, P. Gago, M. C. Martínez, and C. Jiménez-Jorquera: J. Agric. Food Chem. 61 (2013) 9325.

21 L. Escuder-Gilabert and M. Peris: Anal. Chim. Acta 665 (2010) 15.

22 C. Apetrei, I. M. Apetrei, S. Villanueva, J. A. de Saja, F. Gutierrez-Rosales, and M. L. Rodriguez-Mendez: Anal. Chim. Acta 663 (2010) 91.

23 N. Major, K. Marković, M. Krpan, G. Sarić, M. Hruškar, and N. Vahčić: Talanta 85 (2011) 569.

24 X. Cetó, M. Gutiérrez-Capitán, D. Calvo, and M. del Valle: Food Chem. 141 (2013) 2533.

25 C. Söderström, H. Borén, F. Winquist, and C. Krantz-Rülcker: Int. J. Food Microbiol. 83 (2003) 253.

26 G. Zhao, X. Lin, W. Dou, S. Tian, S. Deng, and J. Shi: Anal. Chim. Acta 690 (2011) 240.

27 K. Woertz, C. Tissen, P. Kleinebudde, and J. Breitkreutz: J. Pharm. Biomed. Anal. 55 (2011) 272.

28 J. K. Lorenz, J. P. Reo, O. Hendl, J. H. Worthington, and V. D. Petrossian: Int. J. Pharm. 367 (2009) 65.

29 T. Uchida, Y. Kobayashi, Y. Miyanaga, R. Toukubo, H. Ikezaki, A. Taniguchi, M. Nishikata, and K. Matsuyama: Chem. Pharm. Bull. 49 (2001) 1336.

30 R. Liu, X. Zhang, L. Zhang, X. Gao, H. Li, J. Shi, and X. Li: Exp. Ther. Med. 7 (2014) 1696.

31 X. Zhang, Y. Zhang, Q. Meng, N. Li, and L. Ren: PLoS One 10 (2015) e0137807.

32 Y. Kobayashi, M. Habara, H. Ikezazki, R. Chen, Y. Naito, and K. Toko: Sensors 10 (2010) 3411.

33 K. Toko: Biochemical Sensors (PanStanford Publishing, USA, 2013).

34 P. Omür-Ozbek and A. M. Dietrich: Water Res. 42 (2008) 2598.

35 T. Lee, H. Lin Lee, M. Hsun Tsai, S. L. Cheng, S. W. Lee, J. C. Hu, and L. T. Chen: Biosens. Bioelectron. 43 (2013) 56.

36 M. Adler, A. Mayo, and U. Alon: PLoS Comput. Biol. 10 (2014) e1003781.

37 K. Woertz, C. Tissen, P. Kleinebudde, and J. Breitkreutz: Int. J. Pharm. 400 (2010) 114.

38 A. R. Patel and P. R. Vavia: AAPS Pharm. Sci. Tech. 9 (2008) 544.

39 E. M. M. Del Valle: Process Biochem. 39 (2004) 1033.

40 M. Stojanov, R. Wimmer, and K. L. Larsen: J. Pharm. Sci. 100 (2011) 3177.

41 R. Liu, X. Shi, and Y. Qiao: Chin. J. Exp. Traditional Med. Formulae 15 (2009) 89.

42 S. C. McCleskey, P. N. Floriano, S. L. Wiskur, E. V. Anslyn, and J. T. McDevitt: Tetrahedron 59 (2003) 10089. 